\title{
EFEITO DA CALAGEM E DA ADUBAÇÃO POTÁSSICA SOBRE A ÁREA FOILIAR DE SOJA CONSUMIDA POR LAGARTAS DAS FOLHAS ${ }^{(1)}$
}

\begin{abstract}
ANDRE LUIZ LOURENÇÃO (- $(-)$, Seçāo de Ẽntomologia Fitotécnica, HIPOLITO ASSUNC̣ÃO ANTONIO MASCARENHAS (2), Seção de Leguminosas, PAULO BOLLER GALLO (2), Estaçăo Experimental de Mococa, e ONDINO CLEANTE BATAGLIA (2), Seção de Quimica Analitica, Instituto Agronômico.
\end{abstract}

\section{RESUMO}

$\mathrm{Na}$ Estação Experimental de Mococa (SP), foi estudado o comportamento do cultivar de soja IAC-9, submetido a cinco niveis de adubação potássica e três de calagem, em relação à área foliar comida por lagartas. Houve infestação natural de lagartas no campo experimental, sendo que a espécie predominante foi Anticarsia gemmatalis (Hubner) (Lepidoptera: Noctuidae). Foram coletadas folhas do topo e da parte mediana das plantas para a avaliação visual da porcentagem de área foliar comida e para posterior análise de teores de macro e micronutrientes. Verificou-se que as lagartas apresertaram preferência significativa para se alimentar de plantas das parcelas com calcário em comparação com as plantas das parcelas sem o corretivo. Não se observou influência da adubação potássica na alimentação das lagartas.

\section{INTRODUÇ̃̃O}

A resistência de uma planta em relação ao ataque de um inseto é a expressão da interação entre caracteres hereditários e meio ambiente. Assim sendo, essa resistência se manifesta em determinadas condições; uma série de fatores pode influenciá-la de forma positiva ou negativa,

(1) Recebido para publicação a 26 de janeiro de 1983.

(2) Corn bolsa de suplementação do CNPq. 
segundo ROSSETTO (12), que os agrupou em: a) fatores da planta; b) fatores do inseto e c) fatores ambientes. Entre estes, estão os fatores edáficos, que dizem respeito principalmente à disponibilidade no solo de nutrientes às plantas.

Revisões sobre aspectos nutricionais de plantas afetando seu comportamento em relação a insetos fitófagos foram feitas por MAXWELL (10), RODRIGUES (11) e TINGEY \& SINGH (15).

Relativamente a micronutrientes, LEUCK et alii (8) estudaram o efeito de sais minerais aplicados nas folhas de grama-bermuda (Cynodon dactylon Pers.), milho 'Antigua' e sorgo sobre a alimentação de lagartas de Spodoptera frugiperda (J . E. Smith): verificaram que todos os sais utilizados afetaram adversamente a preferência para a alimentação das lagartas nesses três hospedeiros. SELL \& BODZNICK (14) constataram que a adição de zinco, através de baixos níveis de $\mathrm{ZnS}_{4}$, em dieta para Heliothis virescens (Fabricius), inibiu a pupação, além de interferir negativamente no desenvolvimento larval. WISEMAN et alii (16) observaram que, em milho, a aplicação de zinco proporcionou uma redução no peso de lagartas de $\mathbf{S}$. frugipenda.

Com respeito a macronutrientes, KLOSTERMEYER (5) observou que a adubação nitrogenada em milho proporcionou diferenças no dano de Heliothis armigera (Hubner). Segundo o autor, um aumento em nitrogênio adicionado resultou em menor dano da lagarta. Já SCOTT et alii (13), avaliando o ataque de Ostrinia nubilalis (Hubner) em cruzamentos de milho, em diferentes populaçōes e dosagens de nitrogênio, verificaram que a redução na produção foi maior nas parcelas tratadas que naquelas sem adição de nitrogênio. ALLEN \& SELMAN (1) investigaram a alimentação de lagartas de Pieris brassicae (L.) em folhas de crucíferas com deficiências de nitrogênio, fósforo, potássio e ferro: concluíram que deficiências de nitrogênio e ferro provocaram redução do peso larval, da taxa de crescimento, aumento da mortalidade larval e atraso na pupação; deficiências de fósforo e potássio causaram redução do peso larval e atraso na pupação. LEUCK (7) estudou o efeito da adubação NPK em diferentes combinações desses nutrientes em Pennisetum typhoideum Rich. sobre a alimentação de lagartas de $\mathbf{S}$. frugiperda: folhas das plantas dos tratamentos NP e NPK foram mais preferidas para alimentação que as dos tratamentos N, K, NK, PK, P e testemunha. WISEMAN et alii (17) estudaram a alimentação de lagartas de S. frugiperda e Heliothis zea (Boddie) em folhas de milho 'Antigua' provenientes de plantas adubadas com NPK e com todas as combinações desses nutrientes: ambas as espécies preferiram folhas de plantas que receberam nitrogênio no tratamento às dos tratamentos $\mathrm{P}, \mathrm{K}, \mathrm{PK} \mathrm{e}$ testemunha. Em outro estudo, utilizando apenas a espécie S. frugiperda em milho e as mesmas combinaçōes de NPK, WISEMAN et alii (16) chegaram a resultados semelhantes. MARTINS et alii (9), avaliando a 
influência da adubação nitrogenada em arroz sobre o nível de infestação de Diatraea saccharalis (Fabricius), verificaram que plantas que receberam esse elemento foram mais danificadas por essa broca e que o nível de dano foi altamente relacionado com a dose de $\mathrm{N}$ utilizada. Segundo COUTINHO et alii (3), em sorgo-sacarino, essa broca apresentou indices de infestação crescentes em resposta a aumentos nas dosagens de nitrogênio. Todavia, não foram observados efeitos do calcário dolomítico em diferentes níveis sobre o dano da broca.

O presente trabalho visou estudar o efeito da aplicação de calcário e da adubação potássica em soja sobre a alimentação de lagartas das folhas.

\section{MATERIAL E MÉTODOS}

Na Estação Experimental de Mococa (SP), do Instituto Agronômico, em solo podzólico vermelho-amarelo orto, instalou-se, em 1980, experimento para testar o efeito residual de cinco níveis de adubação com $\mathrm{K}_{2} \mathrm{O}$ e de três níveis de calagem com calcário dolomítico para o cultivar de soja IAC 9. Nesse experimento, no ano agrícola 1981/82, estudou-se o comportamento do cultivar em relação à área foliar comida por lagartas desfolhadoras.

Os tratamentos em parcelas subdivididas foram distribuidos em blocos ao acaso com quatro repetições. As doses $0,3,5$ e $7,0 t /$ ha de calcário constituíram as parcelas e, $0,150,300,450$ e $600 \mathrm{~kg} / \mathrm{ha}$ de $\mathrm{K}_{2} \mathrm{O}$, as subparcelas, as quais foram representadas por sete linhas de $5 \mathrm{~m}$ espaçadas entre si de $0,6 \mathrm{~m}$.

Antes de se realizar a calagem, fez-se análise de solo para o campo experimental. A incorporação das doses de calcário foi efetuada 90 dias antes da semeadura, que ocorreu a 10-08-80, através de grade e arado. As doses de $\mathrm{K}_{2} \mathrm{O}$ foram incorporadas no sulco trinta dias antes da semeadura.

Em 1981/82, foi estudado o primeiro ano de efeito residual. A semeadura do cultivar IAC 9 efetuou-se a 16-10-81. Durante o mês de dezembro de 1981, no campo experimental, ocorreu infestação natural de lagartas das folhas. Em visitas de inspeção feitas nesse período, observou-se que a espécie predominante entre as lagartas era a Anticarsia gemmatalis (Hubner). A 26-01-82, ao final da infestação, época em que as plantas se encontravam no início do estádio reprodutivo, foi realizada amostragem de folhas para avaliação da área foliar comida. Considerando-se a terceira e a quinta linha das subparcelas como linhas úteis, foram coletadas sessenta folhas do topo e sessenta da parte mediana das plantas para cada subparcela. Essa técnica de amostragem foi baseada na metodologia proposta por KOGAN et alii (1977), que recomendam a coleta de vinte foliolos da parte superior e vinte da parte 
mediana das plantas de soja para estimar a porcentagem de desfolhamento. O material coletado foi levado para laboratório em Campinas e mantido em geladeira, sendo retirado apenas para a estimativa visual da porcentagem de área foliar comida pelas lagartas em cada folha, isoladamente, sendo recolocado logo em seguida em geladeira.

Terminada a avaliação, após o devido preparo desse material, foi feita análise química para macro e micronutrientes, segundo o método de BATAGLIA et alii (2); nesse material, também foi feita análise de açúcares, de acordo com DUBOIS et alii (4).

Após a colheita do ensaio, realizou-se novamente análise de solo de cada subparcela.

A análise estatística foi feita em separado para os dades d $\epsilon$ desfolhamento referentes a folhas do topo e da parte mediana: analisaram-se também os teores de macro e micronutrientes. As miédras foram comparadas pelo teste de Tukey a $5 \%$.

\section{RESULTADOS E DISCUSSÃo}

As médias das porcentagens de desfolhamento causado pelas lagartas da soja em folhas do topo e da parte mediand das plantas nos diferentes niveis de calagem e adubação potássica encontram-se no quadro 1. Verifica-se que, tanto na parte superior como na parte média das plantas, as lagartas apresentaram preferência para se alimentar em folhas nas parcelas em que foi aplicado calcário. Todavia, entre ambas as doses de corretivo utilizadas, 3,5 e 7,0t/ha, não foi encontrada diferença significativa para as porcentagens de desfolhamento. Apenas observa-se que na parte mediana o desfolhamento causado pelas lagartas foi ligeiramente maior, embora fossem mantidas as diferenças na preferência para alimentação em plantas das parcelas com e sem calcário.

Com respeito ao $\mathrm{K}_{2} \mathrm{O}$, observa-se que, aparentemente, as doses aplicadas não exerceram influência através das plantas sobre as lagartas, já que nos cinco níveis de adubação e nas duas alturas consideradas nas plantas, não foram encontradas diferenças expressivas de área foliar consumida.

Cumpre mencionar que a produção de soja não apresentou respostas em relação à adubação com $\mathrm{K}_{2} \mathrm{O}$, mas um efeito significativo foi observado em relação à calagem. A testemunha $(0 t / h a)$ teve uma produção de $1.658 \mathrm{~kg} / \mathrm{ha}$, ao passo que as doses de 3,5 e $7,0 \mathrm{t} / \mathrm{ha}$ proporcionaram produções de 2.339 e $2.579 \mathrm{~kg} / \mathrm{ha}$ respectivamente.

No quadro 2, observa-se que, dentre os micronutrientes, apenas boro e zinco sugerem correlação com a área folar consumida por lagartas e também com a calagem, embora somente zinco mostre diferenças significativas em ambas as alturas. Nestas, constata-se o conhe- 
cido efeito depressivo do calcário na concentração de boro e zinco das folhas. Isso equivale a uma maior alimentação das lagartas nas folhas com teores mais baixos de boro e zinco. Para este, existem informações de que sua aplicação em plantas causaram efeitos antibióticos sobre lagartas que nelas se alimentaram $(14,16)$.

QUADRO 1 - Pcrcentagens médias de tárea foliar comida por lagartas em folhas do topo e da parte mediana de plantas de soja cultivar IAC-9 submetidas a cinco níveis de adubação potássica e três níveis de calagem. Mococa, 1981/82

\begin{tabular}{|c|c|c|c|c|c|c|c|}
\hline \multirow{2}{*}{$\begin{array}{l}\text { Posiçāo das } \\
\text { folhas nas } \\
\text { plantas }\end{array}$} & \multirow{2}{*}{ Calcário } & \multicolumn{5}{|c|}{$\mathrm{K}_{2} \mathrm{O}(\mathrm{kg} / \mathrm{ha})$} & \multirow{2}{*}{ Média } \\
\hline & & 0 & 150 & 300 & 450 & 600 & \\
\hline & t/ha & & & $=\%$ & & & \\
\hline Topo & $\begin{array}{r}0 \\
3,5 \\
7,0\end{array}$ & $\begin{array}{r}8,7 \\
15,8 \\
17,0\end{array}$ & $\begin{array}{r}9,3 \\
14,3 \\
13,9\end{array}$ & $\begin{array}{r}7,1 \\
15,8 \\
16,6\end{array}$ & $\begin{array}{r}9,3 \\
16,9 \\
17,1\end{array}$ & $\begin{array}{r}7,0 \\
14,2 \\
13,3\end{array}$ & $\begin{array}{r}8,3 \mathrm{a} \\
15,4 \mathrm{~b} \\
15,6 \mathrm{~b}\end{array}$ \\
\hline Média * & & $13,8 \mathrm{a}$ & $12,5 \mathrm{a}$ & $13,2 \mathrm{a}$ & $14,4 \mathrm{a}$ & $11,5 \mathrm{a}$ & \\
\hline $\begin{array}{l}\text { Parte } \\
\text { mediana }\end{array}$ & $\begin{array}{r}0 \\
3,5 \\
7,0\end{array}$ & $\begin{array}{l}12,1 \\
17,3 \\
21,3\end{array}$ & $\begin{array}{l}10,9 \\
20,9 \\
20,1\end{array}$ & $\begin{array}{l}13,2 \\
20,3 \\
21,3\end{array}$ & $\begin{array}{l}11,8 \\
20,0 \\
19,4\end{array}$ & $\begin{array}{l}10,2 \\
17,7 \\
18,9\end{array}$ & $\begin{array}{l}11,6 \mathrm{a} \\
19,2 \mathrm{~b} \\
20,2 \mathrm{~b}\end{array}$ \\
\hline Média * & & 16,9 a & $17,3 \mathrm{a}$ & $18,3 \mathrm{a}$ & $17,1 \mathrm{a}$ & $15,6 a$ & \\
\hline
\end{tabular}

* Médias seguidas pela mesma letra na coluna não diferem significativamente pelo teste de Tukey a $5 \%$.

* Médias seguidas pela mesma letra na linha não diferem significativamente pelo teste de Tukey a $\mathbf{5 \%}$.

As equações de regressão linear em que se consideraram zinco e boro come variáveis independentes e o desfolhamento como variável dependente acham-se no quadro 3. Nota-se que, nas duas alturas, o coeficiente de correlação é altamente significativo, indicando associação entre desfolha e nível dos elementos.

Entre os macronutrientes, o nitrogênio e o magnésio tiveram seus menores teores nas parcelas sem calcário, crescendo os valores nas duas outras dosagens desse corretivo Houve; portanto, maior alimentação das lagartas em folhas com maior teor de nitrogênio e magnésio, o que, no caso do primeiro, concorda com os trabalhos mais recentes (1, 


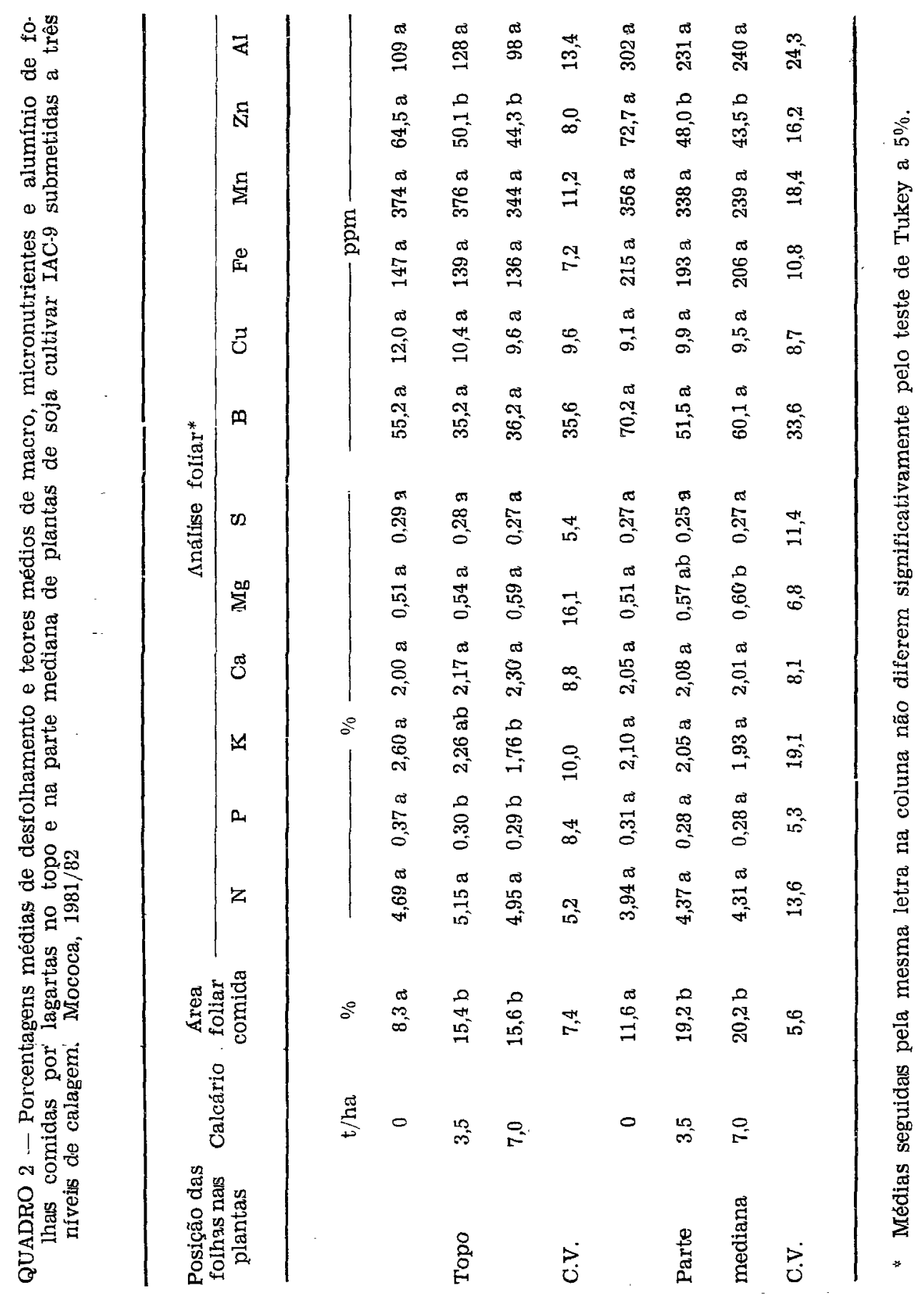


$3,7,9,13,16,17)$. Fósforo e potássio apresentaram tendência contrária, ou seja, tiveram seus maiores teores nas parcelas menos desfolhadas. Diversos autores observaram que a adição isolada desses dois macronutrientes em plantas tornou-as menos preferidas para alimentação de certas lagartas $(\boldsymbol{T}, 16,17)$, embora exista a citação (1) de que a deficiência desses elementos em crucíferas possa induzir efeitos de antibiose em lagartas de $\mathbf{P}$. brassicae.

Outro fator que não foi possível de ser estudado e que poderia ter alta correlação com as variacões de dano das lagartas seria o teor de açúcares nas folhas. No presente trabalho, as folhas amostradas ficaram fora da geladeira durante a viagem e durante a avaliação de dano, tempo suficiente para que o processo de respiração nas folhas provocasse variaçōes altas nos teores de açúcares obtidos.

QUADRO 3 - Equaçōes de regressão linear $(D=$ desfolhamento causado por lagartas) e coeficientes de correlação $(r)$ entre os teores de zinco $(\mathrm{Zn})$ ou boro (B) e área foliar comida em folhas de soja cultivar IAC-9. Mococa, 1981/82

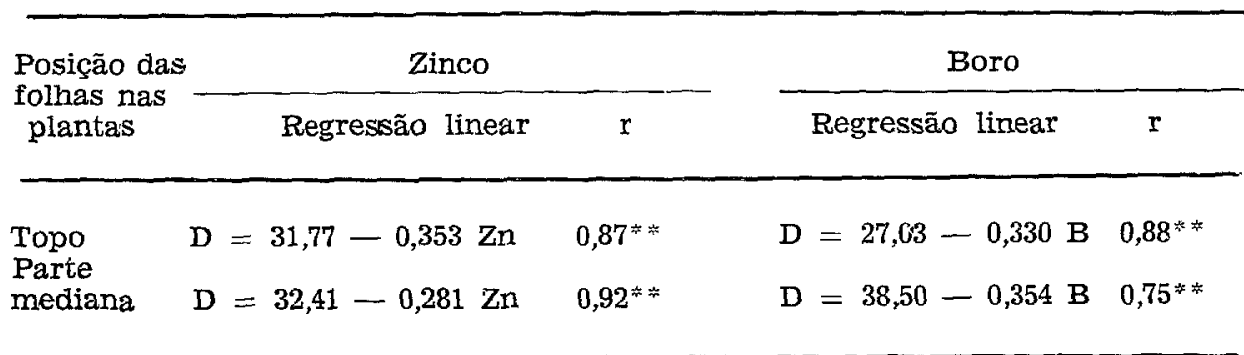

QUADRO $4-\mathrm{pH}$ de amostras de solo onde foi instalado o experimento de cala gem e de adubação potássica em soja, cultivar IAC-9, sobre a alimentação de lagartas desfolhadoras. Moeoca, 1982

\begin{tabular}{ccccccc}
\hline & \multicolumn{7}{c}{$\mathrm{K}_{2} \mathrm{O}(\mathrm{kg} / \mathrm{ha})$} & \\
\hline & 0 & 150 & 300 & 450 & 600 & \\
\hline t/ha & & & & & & \\
0 & 5,0 & 5,0 & 5,0 & 5,1 & 5,1 & 5,0 \\
3,5 & 5,6 & 5,5 & 5,6 & 5,4 & 5,3 & 5,5 \\
7,0 & 5,9 & 5,9 & 6,0 & 6,1 & 5,7 & 5,9 \\
\hline
\end{tabular}


Quanto à acidez do solo, a análise feita antes da calagem, em 1980, relevou ser $5,0 \circ \mathrm{pH}$ da gleba experimental. As médias de $\mathrm{pH}$ das subparcelas, obtidas através de análise realizada após a colheita do ensaio, em 1982, acham-se no quadro 4. Nota-se que os valores aumentaram a cada acréscimo na dose de calcário, o que não ocorreu com os valores de desfolha nos três níveis de calagem.

\section{CONCLUSÕES}

a) A aplicação de calcário dolomítico nas doses de 3,5 e 7,0t/ha em soja cultivar IAC-9 influenciou o comportamento das plantas, tornando-as mais preferidas para alimentação por lagartas desfolhadoras.

b) Nessas condições, o uso de $\mathrm{K}_{2} \mathrm{O}$ nas doses de $150,300,450$ e $600 \mathrm{~kg} /$ ha não teve efeito na alimentação das lagartas.

\section{SUMMARY}

\section{EFFECT OF LIME AND POTASSIC FERTILIZATION ON THE SOYBEAN LEAF AREA EATEN BY CATERPILLARS}

In an experiment of liming and potassic fertilization conducted at Mococa Experimental Station, State of São Paulo, Brazil, there was a natural infestation of caterpillars dominated by Anticarsia gemmatalis (Hbn.) (Lepidoptera: Noctuidae). Samples of the leaves of the top and the middle part of the plants were utilized for visual evaluation of the percentage of foliar area eaten. These leaves were also analysed for macro and micronutrients. The results showed that the caterpillars had preference for leaves in plots that received liming and caused more damage than without liming. Potassium fertilization did not cause any influence on the damage caused by the caterpillars on the soybean leaves.

\section{REFERENCIAS BIBLIOGRAFICAS}

1. ALLEN, M. D. \& SELMAN, I. W. The response of larvae of the large white butterfly (Pieris brassicae (L.) to diets of mineral-deficient leaves. Bulletin of Entomological Research, 48:229-242,1957.

2. BATAGLIA, O. C.; TEIXEIRA, J. P. F.; FURLANI, P. R.; FURLANI, A. M. C.; GALLO, J. R. Métodos de análise química de plantas. Campinas, Instituto Agronômico, 1978. 31p. (Circular, 87)

3. COUTINHO, E. L. M.; BARBOSA, J. C.; BUSOLI, A. C.; LARA, F. M. Efeito de $N, P, \mathrm{~K}$ e calcário sobre a incidência de Diatraea saccharalis (Fabr., 1794) (Lepidoptera - Pyralidae) em sorgo sacarino (Sorgum bicolor (L.) Moench). In: CONGRESSO BRASIIEIRO DE ENTOMOLOGIA, 7, Fortaleza, 1981. p.208.

4. DUBOIS, M.; GILLES, K. A.; HAMILTON, J. K.; REBERS, P. A.; SMITH, $F$. Colorimetric method for determination of sugars and related substances. Analytical Chemistry, 28:350-356, 1956.

5. KLOSTERMEYER, E. C. Effect of soil fertility on corn earworm damage. Journal of Economic Entomology, 43:427-429, 1950.

6. KOGAN, M.; TURNIPSEED, S. G.; SHEPARD, M.; OLIVEIRA, E. B. de; BORGO, A. Pilot insect pest management program for soybean in southern Brazil. Journal of Economic Entomology, 79:659-663, 1977. 
7. LEUCK, D. B. Induced fall armyworm resistance in pearl millet. Journal of Economic Entomology, 65:1608-1611, 1972.

8. - WISEMAN, B. R.; MCMILLIAN, W. W. iutritional plant sprays: effect on fall armyworm feeding preferences. Journal of Economic Entomology, 67:58-60, 1974.

9. MARTINS, J. F. da S.; PINHEIRO, B. S.; LOWE, J. A. Nitrogênio e infestação da broca-do-colmo em arroz irrigado. Pesquisa Agropecuária Brasi leira, 13:23-25, 1978.

10. MAXWELL, F. G. Host plant resistance to insects: Nutritional and pest management relationships. In: RODRIGUEZ, J. G., ed. Insect and mite nutrition. Amsterdam, North Holland Publishing Company, 1972. p.599-609.

11. RODRIGUEZ, J. G. Nutrition of the host and reaction to pests. American Association for the Advancement of Sciences, 61:149-167, 1960.

12. ROSSETTO, C. J. Resistência de plantas aos insetos: apostila da discipli na resistência de plantas aos insetos. Curso pós-graduado de Entomologia ESALQ, USP. 2.ed. Campinas, 1973. 171fl.

13. SCOTT, G. E.; DICKE, F. F.; PENNY, L. H. Effects of first brood European corn borers on single crosses grown at differen nitrogen and plant population levels. Crop Science, 5:261-263, 1965.

14. SELL, D. K. \& BODZNICK, D. A. Effects of dietary $\mathrm{ZnSO}_{4}$ on the growth and feeding of the tobacco budworm, Heliothis virescens. Annals of the Entomological Society of America, 64:850-855, 1971.

15. TINGEY, W. M. \& SINGH, S. R. Environmental factors influencing the magnitude and expression of resistance. In: MAXWELL, F. G. \& JENNINGS, P. R., eds. Breeding plant resistant to insects. New York, John Wiley and Sons, 1980. p.87-114.

16. WISEMAN, B. R.; LEUCK, D. B.; McMILLIAN, W. W. Effect of crop fertilizer on feeding of larvae of fall armyworm on excised leaf sections of corn foliage. Journal of Georgia Entomological Society, 8:136-141, 1973.

17. —_- - - - - - Effects of fertilizers on resistance of Antigua corn to fall armyworm and corn earworm. The Florida Entomologist, $56: 1-6,1973$. 